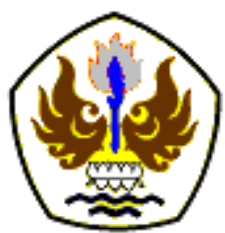

INFOMATEK

Volume 18 Nomor 1 Juni 2016

\title{
PENGUJIAN AKTIVITAS ANTIOKSIDAN TEH BUAH SALAK BONGKOK PADA VARIASI SUHU PENYEDUHAN
}

\author{
Istiyati Inayah", Nabila Marthia \\ Program Studi Teknologi Pangan \\ Fakultas Teknik - Universitas Pasundan
}

\begin{abstract}
Abstrak: Buah salak Bongkok dari desa Bongkok, kecamatan Conggeang kabupaten Sumedang mempunyai rasa asam, sepat, dan agak pahit sehingga tidak diminati masyarakat dan menjadi komoditi terbuang. Untuk memanfaatkan buah salak Bongkok, maka dibuat diversifikasi produk berupa teh buah salak bongkok. Berdasarkan hasil penelitian Afrianti (2006), ekstrak teh buah salak bongkok memiliki aktivitas antioksidan namun hasil seduhan teh buah salak bongkok pada berbagai suhu penyeduhan belum diketahui aktivitas antioksidannya sehingga pada penelitian ini dilakukan pengujian aktivitas antioksidan pada suhu pencelupan $70^{\circ} \mathrm{C}, 80^{\circ} \mathrm{C}$ dan $90^{\circ} \mathrm{C}$. Teh buah salak bongkok diseduh dengan $200 \mathrm{ml}$ air yang bersuhu $70^{\circ} \mathrm{C}, 80^{\circ} \mathrm{C}$ dan $90^{\circ} \mathrm{C}$ selama 3 menit, kemudian dilakukan pengujian aktivitas antioksidan menggunakan metode DPPH. DPPH merupakan senyawa radikal, yang akan diredam oleh sampel yang mengandung antioksidan, sehingga aktivitas antioksidan dilihat dari kemampuan sampel yang dapat meredam $50 \%$ radikal DPPH, dalam hal ini ditunjukkan dengan nilai $\mathrm{IC}_{50}$. Hasil penelitian menunjukkan bahwa suhu terbaik untuk menyeduh teh buah salak Bongkok adalah suhu $90^{\circ} \mathrm{C}$ dengan nilai $I C_{50} 196,34 \mathrm{ppm}$. Nilai $I \mathrm{C}_{50}$ dari air seduhan teh buah salak bongkok untuk suhu penyeduhan $70^{\circ} \mathrm{C}$, dan $80^{\circ} \mathrm{C}$ berturut-turut adalah $309,124 \mathrm{ppm}$ dan $213,665 \mathrm{ppm}$.
\end{abstract}

Kata kunci: Teh buah salak Bongkok, Antioksidan, DPPH

\section{PENDAHULUAN}

Buah salak Bongkok dari desa Bongkok, kecamatan Conggeang kabupaten Sumedang mempunyai rasa asam, sepat, dan agak pahit sehingga tidak diminati masyarakat dan menjadi komoditi terbuang, produksinya pada tahun 2003 s/d 2010 mengalami penurunan hingga 50 persen (Badan Pusat Statistik Jawa Barat, 2010). Harga salak Bongkok di tingkat petani sekitar Rp900,- s/d Rp 1.500,-/kg, sedangkan di tingkat pengecer sekitar Rp 4.000,-/kg (Dinas Pertanian Kab. Sumedang Jawa Barat, 2005), hal ini dapat menyebabkan terjadinya kepunahan dari buah salak varietas Bongkok. Oleh karena itu diperlukan pengembangan buah salak bongkok secara inovatif dengan diversifikasi produk.

\footnotetext{
*istiyatiinayah@unpas.ac.id
} 
Selain itu, berdasarkan hasil penelitian yang dilakukan oleh Afrianti [1] terhadap simplisia buah salak bongkok, buah salak bongkok memiliki senyawa bioaktif yang berperan sebagai antioksidan dan anti hiperuricemia. Hal tersebut menunjang pemanfaatan buah salak bongkok sebagai minuman fungsional berupa teh buah salak bongkok.

Dari hasil karakterisasi simplisia buah salak Bongkok didapatkan bahwa simplisia buah salak bongkok mengandung kadar air 6,15\%, susut pengeringan $9,28 \%$, kadar sari larut air yaitu $76,32 \%$, kadar abu total $2,28 \%$, kadar abu larut air 1,83\%, kadar abu tidak larut asam 0,36 \%, dan kadar sari larut etanol yaitu 48,59\%.Kadar vitamin C pada buah salak Bongkok adalah 8,37 mg / 100 mg (Afrianti, [2]) kadarnya lebih tinggi dibandingkan jenis salak lainnya kandungan vitamin C rata-rata pada buah salak adalah 2,4 $\pm 1,5 \mathrm{mg} / 100$ gram. Penapisan fitokimia terhadap simplisia buah salak Bongkok menunjukkan adanya flavonoid, alkaloid, terpenoid, tannin katekat dan kuinon. Sedangkan saponin tidak ditemukan (Afrianti, [2])
Pengujian antioksidan secara in vitro pada ekstrak dan isolat dengan mengukur serapan 1,1-difenil-2-pikrilhidrazil (DPPH), ekstrak etil asetat menunjukkan peredaman radikal bebas dengan $\mathrm{IC}_{50} 1,6 \mu \mathrm{g} / \mathrm{mL}$. Ekstrak Etanol meredam radikal bebas dengan $\mathrm{IC}_{50} 2,45 \mu \mathrm{g} / \mathrm{mL}$. Ekstrak n-heksan dan ekstrak air tidak menunjukkan aktivitas peredaman radikal bebas.

Struktur senyawa hasil isolasi dan pemurnian ekstrak etil asetat buah salak Bongkok ditetapkan berdasarkan data spektroskopi, yang meliputi spektrum UV, IR, RMI 1-D, dan RMI 2$D$, didapat dua senyawa senyawa yaitu $3 \beta$ hidroksi-stigmastan-5(6)-en dan Asam 2metilester-1-H-pirol-4-karboksilat (Afrianti, [3])Senyawa asam metil pirol-2,4 dikarboksilat menunjukkan peredaman radikal bebas dengan $\mathrm{IC}_{50} 3,27 \mu \mathrm{g} / \mathrm{mL}$ (Afrianti, [3])

Pengujian yang sudah dilakukan adalah pengujian aktivitas antioksidan terhadap ekstrak buah salak bongkok.Sedangkan aktivitas antioksidan dari air seduhan teh buah salak bongkok belum dilakukan. Sehingga dengan dilakukannya penelitian ini maka akan diketahui suhu penyeduhan terbaik dalam menyeduhteh buah salak bongkok agar kandungan 
antioksidan yang terkonsumsi optimal.

Tujuan dari penelitian ini adalah untuk mengetahui aktifitas antioksidan dari air seduhan teh buah salak bongkok pada suhu $70^{\circ} \mathrm{C}, 80^{\circ} \mathrm{C}$ dan $90^{\circ} \mathrm{C}$.

\section{METODOLOGI PENELITIAN}

\section{Alat dan Bahan}

Alat yang digunakan dalam penelitian ini adalah tabung reaksi, rak tabung, mikropipet dan tips, termometer, waterbath, baker glass, kaca arloji, labu ukur, spatula, batang pengaduk, pipet tetes, evaporator dan spektrofotometer UVVisible. Sedangkan bahan yang digunakan dalam penelitian ini adalah teh celup salak Bangkok, aquabidestilata, metanol dan reagen $\mathrm{DPPH}$.

\section{Cara Kerja}

Preparasi sampel dilakukan dengan menimbang teh buah salak bongkok sebesar 6 gram kemudian dimasukkan ke kantung teh celup. Lalu teh diseduhdengan $200 \mathrm{ml}$ akuades yang bersuhu $70^{\circ} \mathrm{C}, 80^{\circ} \mathrm{C}$ dan $90^{\circ} \mathrm{C}$ selama 3 menit. Air seduhan teh buah salak ini yang selanjutnya akan digunakan sebagai sampel penelitian.
Sampel air seduhan teh buah salak diencerkan sampai didapatkan serial konsentrasi 20 ppm, 30 ppm, 40 ppm, 50 ppm dan 60 ppm. Serial konsentrasi ini dibuat dengan mengencerkan stok sampel (100 ppm) dengan penambahan metanol dan DPPH yang volumenya seperti pada Tabel 1 .

Tabel 1

Pembuatan Serial Konsentrasi sampel 20, 30, 40, 50 dan 60 ppm

\begin{tabular}{|l|l|l|l|}
\hline \multirow{2}{*}{$\begin{array}{c}\text { Sampel } \\
\text { (ppm) }\end{array}$} & \multicolumn{3}{|c|}{ Volume (ml) } \\
\cline { 2 - 4 } & Sampel & Metanol & DPPH \\
\hline 20 & 1 & 3 & 1 \\
\hline 30 & 1,5 & 2,5 & 1 \\
\hline 40 & 2 & 2 & 2 \\
\hline 50 & 2,5 & 1,5 & 1 \\
\hline 60 & 3 & 1 & 1 \\
\hline
\end{tabular}

Kelima tabung reaksi yang sudah diisi sampel, metanol dan DPPH diinkubasi selama 30 menit pada suhu ruang, kemudian diukur absorbansinya pada panjang gelombang 517 nm.Dari nilai absorbansi sampel dan DPPH yang didapat kemudian dicari \% aktivitas antioksidan dengan memasukkan nilai absorbansi pada persamaanberikut:

$\%$ AktivitasAntioksidan $=\frac{(\text { Absorbansi DPPH }- \text { Absorbansi Sampel }) \times 100 \%}{\text { Absorbansi DPPH }}$

Setelah didapatkan \% aktivitas antioksidan, kemudian dicari nilai $\mathrm{IC}_{50}$ sampel dengan cara membuat grafik linear, hubungan antara 
konsentrasi sampel $(\mathrm{x})$ dengan $\%$ aktivitas antioksidan sampel $(y)$, sehingga didapatkan persamaan regresi linearnya $(y=a x+b)$. Nilai $\mathrm{IC}_{50}$ didapatkan dengan mengganti nilai $\mathrm{y}$ dengan angka 50 .

\section{HASIL DAN PEMBAHASAN}

Pengujian aktivitas antioksidan dilakukan dengan menentukan nilai $I_{50}$ teh buah salak bongkok, yaitu konsentrasi sampel yang dapat meredam $50 \%$ radikal DPPH. Peredaman radikal DPPH dapat diamati melalui penurunan nilai absorbansi sampel (\% aktivitas antioksidan) yang dianalisis menggunakan metode spektrofotometri pada panjang gelombang 517 nm. Hasil perhitungan nilai $I_{50}$ untuk air seduhan teh buah salak bongkok dengan suhu penyeduhan $70^{\circ} \mathrm{C}, 80^{\circ} \mathrm{C}, 90^{\circ} \mathrm{Cdapat}$ dilihat pada Tabel 2, 3 dan 4 .

Pada penelitian ini dilakukan pengukuran absorbansi terhadap 5 serial konsentrasi sampel teh buah salak yaitu 20 ppm, 30 ppm, 50 ppm, 60 ppm dan 80 ppm, untuk mendapatkan persamaan regresi linear. Berdasarkan persamaan regresi linear, maka dapat diperoleh nilai $I_{50}$ dengan mengganti nilai y dengan angka 50. Grafik regresi linear untuk sampel teh buah salak dengan variasi suhu penyeduhan $70^{\circ} \mathrm{C}, 80^{\circ} \mathrm{C}, 90^{\circ} \mathrm{C}$ dapat dilihat pada Gambar 1,2 dan 3.

Tabel 2.

Hasil perhitungan nilai IC $_{50}$ untuk air seduhan teh buah salak bongkok dengan suhu penyeduhan

\begin{tabular}{|c|c|c|c|c|}
\hline & & $70^{\circ}$ & & \\
\hline \multicolumn{5}{|c|}{ Suhu Penyeduhan } \\
\hline Sampe & Absor & $\%$ aktivitas & Persamaan & $\mathrm{IC}_{50}$ \\
\hline I (ppm) & bansi & antioksidan & linier & (ppm) \\
\hline DPPH & 0,91 & & \multirow{6}{*}{$\begin{array}{c}Y=0,1595 x \\
0+0,6948\end{array}$} & \multirow{6}{*}{309,124} \\
\hline 20 & 0,878 & 3,516 & & \\
\hline 30 & 0,86 & 5,495 & & \\
\hline 50 & 0,831 & 8,681 & & \\
\hline 60 & 0,807 & 11,319 & & \\
\hline 80 & 0,794 & 12747 & & \\
\hline
\end{tabular}

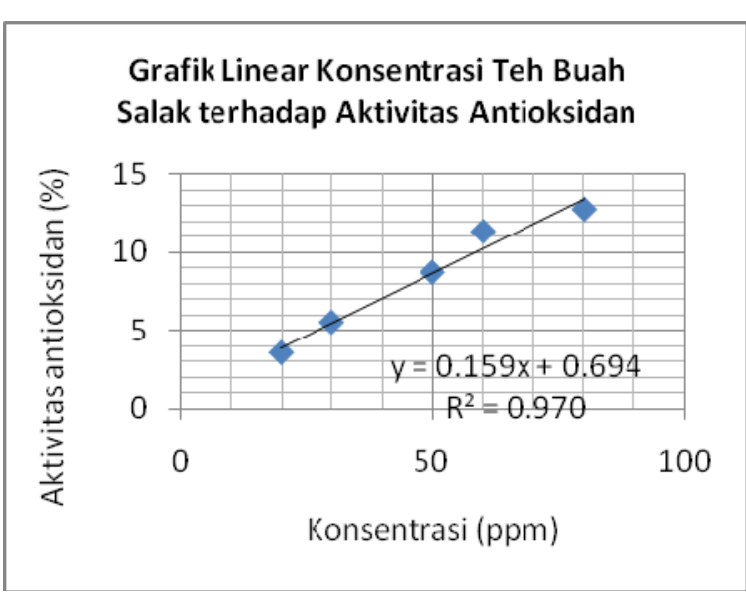

Gambar 1.

Grafik Linear Konsentrasi Teh Buah Salak Bongkok pada Suhu Penyeduhan $70^{\circ} \mathrm{C}$ terhadap Aktivitas Antioksidannya 
Tabel 3.

Hasil perhitungan nilai $\mathrm{IC}_{50}$ untuk air seduhan teh buah salak bongkok dengan suhu penyeduhan $80^{\circ} \mathrm{C}$

\begin{tabular}{|c|c|c|c|c|}
\hline \multicolumn{5}{|c|}{ Suhu Penyeduhan $80^{\circ} \mathrm{C}$} \\
\hline $\begin{array}{c}\text { Sampel } \\
\text { (ppm) }\end{array}$ & Absorbansi & $\begin{array}{l}\% \text { aktivitas } \\
\text { antioksidan }\end{array}$ & $\begin{array}{c}\text { Persamaan } \\
\text { linear }\end{array}$ & $\begin{array}{c}\mathrm{IC}_{50} \\
(\mathrm{ppm})\end{array}$ \\
\hline DPPH & 0,91 & & \multirow{6}{*}{$\begin{array}{c}y=0,2571 x- \\
4,9334\end{array}$} & \multirow{6}{*}{$\begin{array}{l}213 \\
665\end{array}$} \\
\hline 20 & 0,927 & $-1,868$ & & \\
\hline 30 & 0,86 & 5,495 & & \\
\hline 40 & 0,851 & 6,484 & & \\
\hline 50 & 0,8 & 12,088 & & \\
\hline 60 & 0,775 & 14,835 & & \\
\hline
\end{tabular}

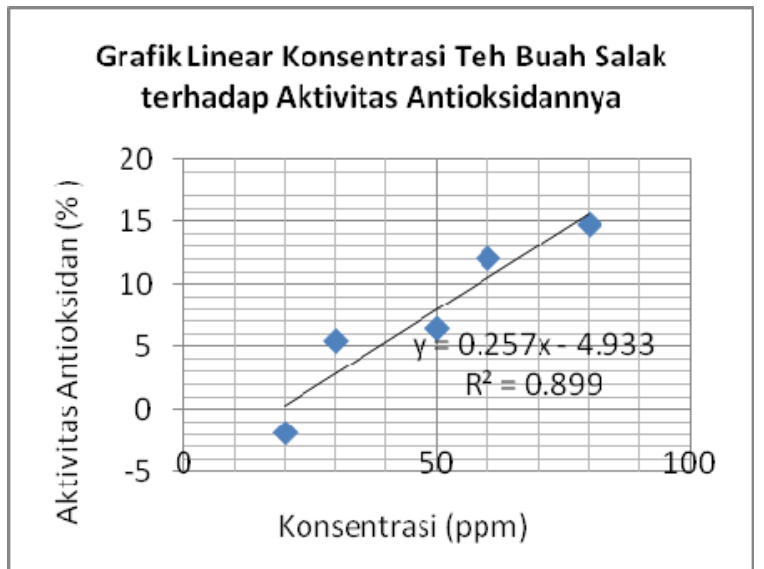

Gambar 2.

Grafik Linear Konsentrasi Teh Buah Salak Bongkok pada Suhu Penyeduhan $80^{\circ} \mathrm{C}$ terhadap Aktivitas Antioksidannya
Tabel 4.

Hasil perhitungan nilai IC50 untuk air seduhan teh buah salak bongkok dengan suhu penyeduhan $90^{\circ} \mathrm{C}$

\begin{tabular}{|c|c|c|c|c|}
\hline & Sur & Penyeduhan & $0^{\circ} \mathrm{C}$ & \\
\hline $\begin{array}{c}\text { Sampel } \\
(\mathrm{ppm})\end{array}$ & Absorbansi & $\begin{array}{l}\% \text { aktivitas } \\
\text { antioksidan }\end{array}$ & $\begin{array}{l}\text { Persamaan } \\
\text { linear }\end{array}$ & $\begin{array}{l}\mathrm{IC}_{50} \\
(\mathrm{ppm})\end{array}$ \\
\hline DPPH & 0,91 & & \multirow{6}{*}{$\begin{array}{l}y=0,2363 x \\
+3,604\end{array}$} & \multirow{6}{*}{$\begin{array}{r}196, \\
344\end{array}$} \\
\hline 20 & 0,832 & 8,571 & & \\
\hline 30 & 0,818 & 10,109 & & \\
\hline 40 & 0,786 & 13,626 & & \\
\hline 50 & 0,773 & 15,0549 & & \\
\hline 60 & 0,747 & 17,912 & & \\
\hline
\end{tabular}

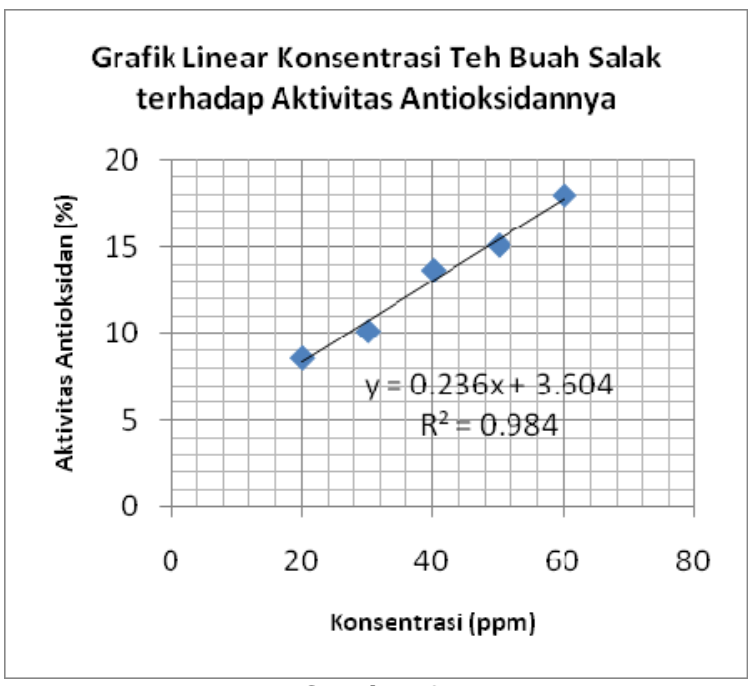

Gambar 3.

Grafik Linear Konsentrasi Teh Buah Salak Bongkok pada Suhu Penyeduhan $90^{\circ} \mathrm{C}$ terhadap Aktivitas Antioksidannya

Dari hasil pengujian aktivitas antioksidan sampel teh buah salak yang diseduh dalam air dengan berbagai variasi suhu (Gambar 4), didapatkan bahwa nilai $\mathrm{IC}_{50}$ untuk air seduhan teh buah salak bongkok dengan suhu penyeduhan $70^{\circ} \mathrm{C}$ adalah 309,124 ppm sedangkan untuk suhu 
penyeduhan $80^{\circ} \mathrm{C}$ adalah $213,665 \mathrm{ppm}$ dan untuk suhu penyeduhan $90^{\circ} \mathrm{C}$ adalah 196,344 ppm. Berdasarkan hasil penelitian, terlihat bahwa suhu penyeduhan $90^{\circ} \mathrm{C}$ merupakan suhu penyeduhan terbaik dilhat dari aktivitas antioksidannya. Aktivitas antioksidan diukur melalui perhitungan nilai $I_{50}$, yaitu konsentrasi sampel (ppm) yang menunjukkan kemampuan meredam radikal bebas DPPH sebesar $50 \%$. Jadi semakin rendah nilai $\mathrm{IC}_{50}$ maka aktivitas antioksidannya semakin baik.

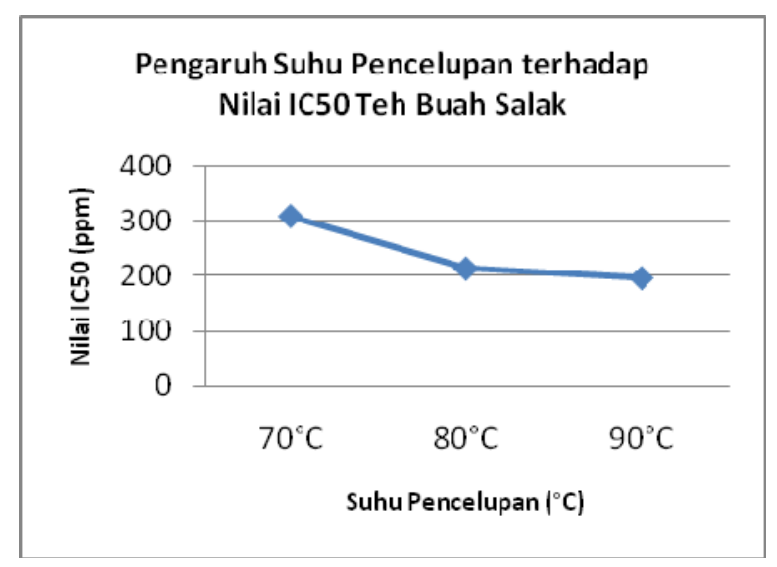

Gambar 4.

Grafik Suhu Pencelupan terhadap Nilai $I_{50}$

Hasil penelitian menunjukkan bahwa suhu penyeduhan dapat mempengaruhi aktivitas antioksidan dari teh buah salak bongkok yang ditunjukkan dari peningkatan aktivitas antioksidan yang seiring dengan peningkatan suhu penyeduhan. Hal ini sesuai dengan hasil penelitian yang dilakukan Dewanto [4]terhadap buah tomat yang menunjukkan peningkatan total aktivitas antioksidan ketika tomat tersebut diproses pada suhu tinggi.

Suhu tinggi dapat mempengaruhi proses ekstraksi senyawa dalam suatu bahan. Untuk senyawa yang tahan panas, suhu tinggi dapat meningkatkan perolehan ekstrak, akan tetapi untuk senyawa yang sensitif terhadap suhu tinggi proses ekstraksi justru menurunkan perolehan ekstrak. Di dalam ekstrak teh buah salak bongkok, tidak hanya terdapat satu jenis senyawa yang berperan sebagai antioksidan. Namun jika dilihat dari kecenderungan peningkatan aktivitas antioksidan ketika diseduh pada suhu tinggi, sampai mencapai suhu $90^{\circ} \mathrm{C}$, maka dapat disimpulkan bahwa senyawa yang berpengaruh sebagai antioksidan adalah senyawa yang tahan panas.

Pengujian yang dilakukan pada penelitian ini adalah total aktivitas antioksidan yang melihat tingkat peredaman senyawa radikal DPPH oleh 
senyawa-senyawa yang berada dalam air seduhan teh buah salak bongkok sehingga ada pengaruh dari suhu penyeduhan terhadap aktivitas antioksidannya. Menurut Swasono [5],antioksidan dapat berbentuk gizi seperti Vitamin $\mathrm{E}$ dan $\mathrm{C}$, non-gizi (pigmen karoten, likopen, flavonoid dan klorofil) dan enzim (glutation peroksidase, koenzim Q10 atau ubiquinon). Berdasarkan penelitian yang dilakukan oleh Afrianti [3], penapisan fitokimia terhadap simplisia buah salak Bongkok menunjukkan adanya senyawa flavonoid, alkaloid, terpenoid, tannin katekat dan kuinon yang berpotensi sebagai antioksidan. Berdasarkan isolasi senyawa yang dilakukan Afrianti [3] terhadap ekstrak buah salak, diperoleh senyawa metil pirol-2,4 dikarboksilat yang diduga kuat bertanggung jawab terhadap aktivitas antioksidan karena strukturnya memiliki ikatan rangkap yang terkonjugasi.

\section{KESIMPULAN}

Suhu penyeduhan berpengaruh terhadap aktivitas antioksidan teh buah salak bongkok dengan nilai $\mathrm{IC}_{50}$ untuk air seduhan teh salak dengan suhu penyeduhan $70^{\circ} \mathrm{C}, 80^{\circ} \mathrm{C}$ dan $90^{\circ} \mathrm{C}$ berturut-turut adalah 309,124 ppm, 213,665 ppm dan 196,344 ppm.

\section{DAFTAR RUJUKAN}

[1] Afrianti LH, Sukandar EY, Ibrahim S, Adnyana IK, 2006a. Aktivitas antioksidan ekstrak daging buah salak varietas Bongkok ( Salacca Edulis Reinw.). J Acta Pharmaceutica, Vol.XXXI,NO 1, Maret 2006. ISSN : 0216-616X

[2] Afrianti LH, Sukandar EY, Ibrahim S, Adnyana IK, 2006b. Isolasi, elusidasi struktur dan aktivitas antioksidan ekstrak buah salak Bongkok. Prosiding Seminar Nasional Persatuan Ahli Teknologi Pangan Indonesia (PATPI),UGM Yogyakarta

[3] Afrianti LH, Sukandar EY, Ibrahim S, Adnyana IK.2010a. Senyawa asam 2metilester-1-H-pirol-4karboksilat dalam ekstrak etil asetat buah salak Bongkok sebagai antiokisdan dan antihiperurikemia.

J. Teknologi dan Industri Pangan. Vol XXI(1);66-72. ISSN 1979-7788

[4] Dewanto, Veronica, Xainzhong Wu, Kafui K. Adom, Rui Hai Liu. 2002. Thermal Processing Enhances the Nutritional Value 
Infomatek Volume 18 Nomor 1 Juni 2016 : 57 - 64

of Tomatoes by Increasing Total Antioxidant

Activity. Journal of Agricultural and Food

Chemistry (10) 3010-3014

[5] Swasono, R. Tamat, T. Wikanta, Lina S.

Maulina. Aktivitas Antioksidan dan
Toksisitas Senyawa Bioaktif dari Ekstrak

Rumput Laut Hijau Ulva reticulat. Jurnal IImu Kefarmasian Indonesia Vol 5 No.1 (31-

36) 